The following pages constitute the final, accepted and revised manuscript of the article:

Essén, Birgitta and Sjöberg, Nils-Otto and Gudmundsson, Saemundur and Ostergren, P-O and Lindqvist, Pelle G

"No association between female circumcision and prolonged labour: a case control study of immigrant women giving birth in Sweden.”

Eur J Obstet Gynecol Reprod Biol. 2005 Aug 1;121(2):182-5.

Publisher: Elsevier

Use of alternative location to go to the published version of the article requires journal subscription.

Alternative location: http://dx.doi.org/10.1016/j.ejogrb.2004.12.010 


\section{No association between female circumcision and prolonged labour: a case control study of immigrant women giving birth in Sweden}

Birgitta Essén ${ }^{1}$, Nils-Otto Sjöberg ${ }^{1}$, Saemundur Gudmundsson ${ }^{1}$, P-O Östergren ${ }^{2}$, Pelle G Lindqvist $^{1}$

${ }^{1}$ Department of Obstetrics and Gynecology, University Hospital MAS, Malmö, Sweden

${ }^{2}$ Department of Community Medicine, University Hospital MAS, Malmö, Sweden

Corresponding author:

Dr Birgitta Essén

Department of Obstetrics and Gynaecology

University Hospital MAS

SE-205 02 Malmö, Sweden

Telephone: +4640310000

Fax: +4640962600

Birgitta.Essen@obst.mas.lu.se

Keywords: Female circumcision, prolonged labour, immigrants 


\section{ABSTRACT}

Objective: Several authors' associate female genital circumcision with obstructed and prolonged labour, but the World Health Organization recently stated that no scientific evidence confirms such a relationship. The object of this study was to compare the duration of the second stage of labour between circumcised and non-circumcised women in a highincome community in Europe.

Methods: Sixty-eight circumcised nulliparous women originally from the Horn of Africa were compared to a group of 2486 non-circumcised nulliparous who gave birth at a university hospital setting in Sweden, 1990-1996. Defibulation was routinely performed during labour. Findings: Circumcised women were found to have had second stage labour, which was significantly statistically shorter (35/53 minutes, respectively $\mathrm{p}=<0.001$ ), and a lower risk of prolonged labour than the non-circumcised group.

Conclusions: Prolonged labour does not seem to be associated to female genital circumcision in affluent societies with high standards of obstetric care. 


\section{INTRODUCTION}

Complications related to female genital circumcision (also referred as genital mutilation or genital cutting) have often been described in women from certain parts of Africa, but little attention has been given to the question of obstetric complications related to circumcision after such women have migrated from a low- to a high-income country. Some authors have claimed that prolongation of the second stage of labour, purportedly in consequence of dystocia induced by scar tissue as a sequel of circumcision, may culminate in obstructed labour, cerebral damage, asphyxia, and fetal death [1-8]. It seems of importance to revalidate the information about obstetrical complications, which has often been based on recitations from earlier articles or observations. Few controlled studies on this subject have been published [9-13].

A recent investigation has shown that women in Sweden who immigrated predominantly from Ethiopia and Somalia represent an ethnic group with increased perinatal mortality [14]. Sub-optimal factors in obstetric care were often likely to result in perinatal death in this immigrant group [15]. However, circumcision per se was not found to be directly related to perinatal death [16]. This raises the question of whether or not there is a tendency toward a longer duration of labour among circumcised women giving birth in a community with high standards of obstetrical care. 


\section{METHODS}

Sixty-eight nulliparous singletons circumcised women delivering in the maternity ward of University Hospital, Malmö, Sweden, in 1990 — 1996, the only such unit in the city, were compared with the cohort of 2486 non-circumcised nulliparous women with singleton pregnancies, who gave birth at the same institution in 1995-1996. The number of home deliveries is very low in Sweden and all immigrants use the obstetric service at hospital level. Obstetrical information was provided by the hospital database. The medical records of all women of Ethiopian and Somali origin were identified and scrutinised for their genital status. The classification of circumcision was not always described with the terms of WHO's classification. However, the most common form of described genital status was found to be infibulation, the excision known to be the most extensive form of circumcision in Somalia and Ethiopia $[17,18]$. Infibulation involves removal of the clitoris, minor labia and parts of the major labia, and a stitching together of the remains of the labia, leaving a small opening in the vulva. The hospital has had guidelines on how to handle circumcised women during labour for more than ten years. Defibulation (incision of the bridge of skin that covers the vulva after infibulation) is routinely performed and episiotomy when needed independently of whether the women is circumcised or not (Fig 1).

The second stage of labour was defined as the period from complete cervical dilatation to delivery. Prolongation of labour was defined as a second stage of labour exceeding 60 minutes. Birthweight deviation was defined as birthweight minus expected weight for gestational age, divided by expected birthweight (expressed as a percentage). Small or large for-gestational-age was defined as mean \pm 2 SD of birthweight [19].

A Mann-Whitney test was used to compare differences between the groups. The relative risk of prolonged labour was estimated by means of odds ratios (OR), 95\% confidence intervals (CIs) are reported. A multivariate analysis was performed by means of 
logistic regression. Prolonged labour was used as dependent variable, and maternal age, epidural anaesthesia, episiotomy, augment with oxytocin and birthweight deviation as independent variables. 


\section{RESULTS}

The two groups were compared with regard to five background factors (Table 1). The second stage of labour among circumcised women was found to be shorter in comparison with noncircumcised women (median time 35/53 minutes, respectively, $\mathrm{p}<0.001$ ). The estimated OR for prolonged labour was statistically lower by a significant amount among circumcised women, both in terms of bivariate measurement and after adjustment (Table 2). Adjustment for augment with oxytocin, epidural anaesthesia, birthweight deviation and maternal age did not yield a statistically significant change in the risk for prolonged labour. The frequency of mediolateral episiotomy was 65\% among circumcised women and 40\% among noncircumcised women. When episiotomy was used as an adjusting variable, it even increased the differences between the two groups regarding the risk of prolonged labour (not in table). Women delivered by Caesarean section (15/361, respectively) were excluded. Circumcised women were delivered by C-sections due to fetal distress $(n=9)$, preeclampsia $(n=2)$, infection $(n=3)$ or breech presentation $(n=1)$. Only one of the emergency operations was initiated with a fully dilated cervix, and was due to fetal distress, where the obstetrician had difficulties in applying the vacuum extraction before defibulation was performed. 


\section{DISCUSSION}

Circumcised women, the majority of whom had undergone infibulation, were found to have had second stage labour that was significantly shorter, and a lower risk of prolonged labour than the non-circumcised group. Our results are in agreement with the recent statement by WHO that announced that no documented evidence has been found to confirm a relationship between obstructed and prolonged labour and genital circumcision [20]. Nor do recently performed literature reviews find supporting evidence [21,22].

It is unlikely that scar tissue resulting from circumcision would be too tough to be torn by uterine contractions, as the frequency of both prolonged labour and instrumental vaginal delivery was not found to be higher among circumcised women. Other forms of scar tissue, for instance due to earlier episiotomy have, to our knowledge, not been related to prolonged labour. In fact, since any form of circumcision does not affect the elasticity of the birth canal itself, there should be no reason for obstructed or prolonged labour. An earlier study from Saudi Arabia reported a significant prolongation of the second stage of labour in circumcised women, as compared to a non-circumcised group of different ethnic backgrounds [11]. However, the author concluded that the second stage of labour might not be prolonged if steps are taken to defibulate the women. A recent study of complications among ethnic Somalis in Norway reported an increased frequency of prolonged second stage of labour. However, data were based on ICD diagnose number, and prolonged labour was not measured as real time of delivery, like in this study. The authors stress that midwives and obstetrician are not familiar with the management of circumcised women. They have lack of experience with the defibulation procedure and routine episiotomy was not studied [9]. Defibulation was routinely performed in the present study, as well as episiotomy, as needed, which may account for the lack of correlation between circumcision and prolonged labour in the deliveries of these circumcised women in Sweden. The Swedish health authorities as having 
one of the best routine and guidelines of how to meet circumcised women have recently nominated the hospital. It seems to be important to educate health providers when they are confronted by new groups of patients. Theoretically, the immigrant-circumcised women in this study might represent a positively selected group regarding long-time complications due to circumcision (as large keloid scar or cysts) [17]. No evidence of vaginal stenosis was found, as had been observed in an earlier study among multiparous circumcised women who gave birth in low-income regions.

A limitation of this study is that it has not been possible to assemble a noncircumcised control group of women from the Horn of Africa who have migrated to Sweden, because there are very few of them. However, we have not found evidence suggesting that ethnic background per se should be an independent risk factor for prolonged labour [23, 24]. Among immigrants from low-income countries it is known that some of them, in order to avoid having a large fetus and the complications it might bring during labour, many women eat less during pregnancy [25]. However, control of birthweight deviation did not change the results (Table 2). The variable augment with oxytocin was a risk factor for prolonged labour. The interpretation is that oxytocin per se is not related to prolonged labour but is more often given during delivery with slow progress (Table 2). Further controlled studies could be of value, especially in regions where circumcision still persists. However, it could be difficult to assemble a non-circumcised control group even in these areas. Larsen et al. did not find any significantly different risk of prolonged labour comparing circumcised and uncircumcised women [12].

We have not been able to consider effects of maternal anxiety on the duration of labour. An interesting study has recently shown that women who where worried about there delivery and their own health had a shorter second stage of labour compared to women who were worried about their child's condition [26]. 
The United Nations has recommended that governments adopt clear national policies to abolish circumcision, and also intensify educational programmes to inform citizens about its harmfulness. Prevention is not only a matter of educating families about this tradition. It is also a matter of providing health care professionals with precise information as to risks and potential complications in the delivery of circumcised women. This will enable medical personnel to administer the best possible care to such women, both in low- and high resource areas of the world.

The results of our investigation should not be taken as a reason to abstain from criticising the practice of female genital circumcision. On the contrary, it should help focus attention on the real but separate problems of circumcision and delivery with an enlarged Europe with new citizens. Prolonged labour in instances of patients with genital circumcision may not be encountered in affluent countries precisely because of the presence of another factor: high standards of antenatal and obstetric care, which include routines of how to handle circumcised women. 


\section{ACKNOWLEDGEMENT}

This study has been supported by grants from the Faculty of Medicine, Lund University; the University Hospital MAS, Malmö; General Maternity Hospital Foundation, European

Commission DAPHNE Programme (JA/DAP/02/163/WYC) and the Foundation Mayflower, Sweden. 


\section{CONTRIBUTORS}

Birgitta Essén (BE) and Pelle Lindqvist (PL) had the original idea for the study and were responsible for the study design and interpretation of the data. BE is the guarantor: she analysed, wrote and approved the final version of the paper in discussion with the group of

authors, among whom especially P-O Östergren, PL, and Saemundur Gudmundsson had an active part in the writing process. 


\section{REFERENCES}

[1] Toubia N. Female circumcision as a public health issue. N Engl J Med 1994;331:712-6.

[2] Arbesman M, Kahler L, Buck GM. Assessment of the impact of female circumcision on the gynecological, genitourinary and obstetrical health problems of women from Somalia: literature review and case series. Women Health 1993;20:27-42.

[3] Paul BK. Maternal mortality in Africa: 1980-87. Soc Sci Med 1993;37:745-52.

[4] Baker CA, Gilson GJ, Vill MD, Curet LB. Female circumcision: obstetric issues. Am J Obstet Gynecol 1993;169:1616-8.

[5] Elchalal U, Ben-Ami B, Gillis R, Brzezinski A. Ritualistic female genital mutilation: current status and future outlook. Obstet Gynecol Surv 1997;52:643-51.

[6] Lightfoot-Klein H, Shaw E. Special needs of ritually circumcised women patients. J Obstet Gynecol Neonatal Nurs 1991;20:102-7.

[7] Omar M. Female circumcision and child mortality in urban Somalia. Genus 1991;47:203-223.

[8] Rushwan H. Female genital mutilation (FGM) management during pregnancy, childbirth and the postpartum period. Int J Gynaecol Obstet 2000;70:99-104.

[9] Vangen S, Stoltenberg C, Skrondal A, Magnus P, Stray-Pedersen B. Cesarean section among immigrants in Norway. Acta Obstet Gynecol Scand 2000;79:553-8.

[10] Berardi JC, Teillet JF, Godard J, Laloux V, Allane P, Franjou MH. Obstetrical consequences of female circumcision. Study in 71 circumcised African women. $\mathrm{J}$ Gynecol Obstet Biol Reprod (Paris) 1985;14:743-6.

[11] De Silva S. Obstetric sequelae of female circumcision. Eur J Obstet Gynecol Reprod Biol 1989;32:233-40. 
[12] Larsen U, Okonofua FE. Female circumcision and obstetric complications. Int J Gynaecol Obstet 2002;77:255-65.

[13] Jones H, Diop N, Askew I, Kabore I. Female genital cutting practices in Burkina Faso and Mali and their negative health outcomes. Stud Fam Plann 1999;30:219-30.

[14] Essen B, Hanson BS, Ostergren PO, Lindquist PG, Gudmundsson S. Increased perinatal mortality among sub-Saharan immigrants in a city-population in Sweden. Acta Obstet Gynecol Scand 2000;79:737-43.

[15] Essen B, Bodker B, Sjoberg NO et al. Are some perinatal deaths in immigrant groups linked to suboptimal perinatal care services? Br J Obstet Gyneacol 2002;109:677-82.

[16] Essen B, Bodker B, Sjoberg NO, Gudmundsson S, Ostergren PO, Langhoff-Roos J. Is there an association between female circumcision and perinatal death? Bull World Health Organ 2002;80:629-32.

[17] Dirie MA, Lindmark G. The risk of medical complications after female circumcision. East Afr Med J 1992;69:479-82.

[18] Shell-Duncan B, Hernlund Y. Female circumcision in Africa: Dimensions of the practice and debates. London: Lynner Rienner Publishers; 2000.

[19] Marsal K, Persson PH, Larsen T, Lilja H, Selbing A, Sultan B. Intrauterine growth curves based on ultrasonically estimated foetal weights. Acta Paediatr 1996;85:843-8.

[20] World Health Organization. Female genital mutilation. An overview. Genéve: WHO Graphics; 1998.

[21] Shell-Duncan B. The medicalization of female "circumcision": harm reduction or promotion of a dangerous practice? Soc Sci Med 2001;52:1013-28. 
[22] Obermeyer CM. Female genital surgeries: the known, the unknown, and the unknowable. Med Anthropol Q 1999;13:79-106.

[23] Albers LL, Schiff M, Gorwoda JG. The length of active labor in normal pregnancies. Obstet Gynecol 1996;87:355-9.

[24] Duignan NM, Studd JW, Hughes AO. Characteristics of normal labour in different racial groups. Br J Obstet Gynaecol 1975;82:593-601.

[25] Essen B, Johnsdotter S, Hovelius B et al. Qualitative study of pregnancy and childbirth experiences in Somalian women resident in Sweden. Br J Obstet Gyneacol 2000;107:1507-12.

[26] Sjöström K. Some effects of maternal anxiety on fetus and on pregnancy outcome [Dissertation]. Malmö: Malmö University Hospital, Lund University; 2002. http://www.lub.lu.se/cgi-bin/show_diss.pl/med_661.html 
Table 1 Background factors among circumcised and non-circumcised nulliparous women giving birth in Malmö, Sweden, 1990—96

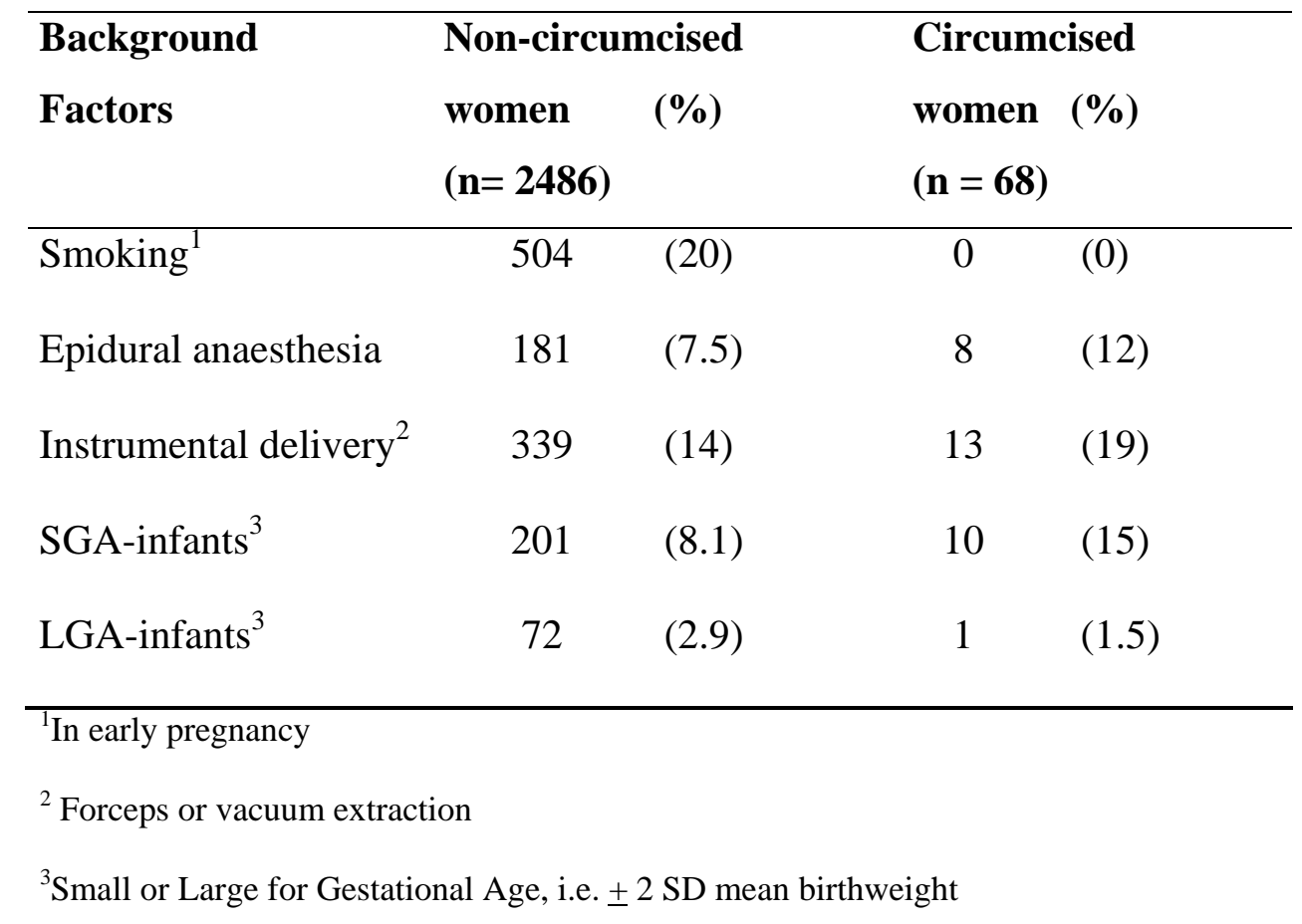


Table 2 Bivariate and adjusted relative risk regarding prolonged labour among circumcised $(n=68)$ and non-circumcised nulliparous women $(n=2486)$, giving birth in Sweden 1990-96

\section{Variables}

Bivariate OR (95\% CI) $\quad$ Adjusted $^{4}$ OR (95\% CI)

\section{Prolonged labour $^{1} \quad$ Prolonged labour $^{1}$}

Circumcised vs. non-circumcised $0.3 \quad(0.2-0.5)$

$0.2 \quad(0.2-0.5)$

Maternal age ${ }^{2}$

1.1

Birthweight deviation $^{3}$

Epidural anaesthesia

Augment with oxytocin

$3.3 \quad(2.8-4.0)$

\footnotetext{
${ }^{1}$ Second stage of labour $>60 \mathrm{~min}$.

${ }^{2}$ The OR is presented as risk for every additional 10 years period

${ }^{3}$ The OR is presented as risk for every $10 \%$ increase in birth-weight deviation

${ }^{4}$ Adjusted for age, birthweight deviation, epidural anaesthesia, and augment with oxytocin
} 
Table 1 Background factors among circumcised and non-circumcised nulliparous women giving birth in Malmö, Sweden, 1990—96

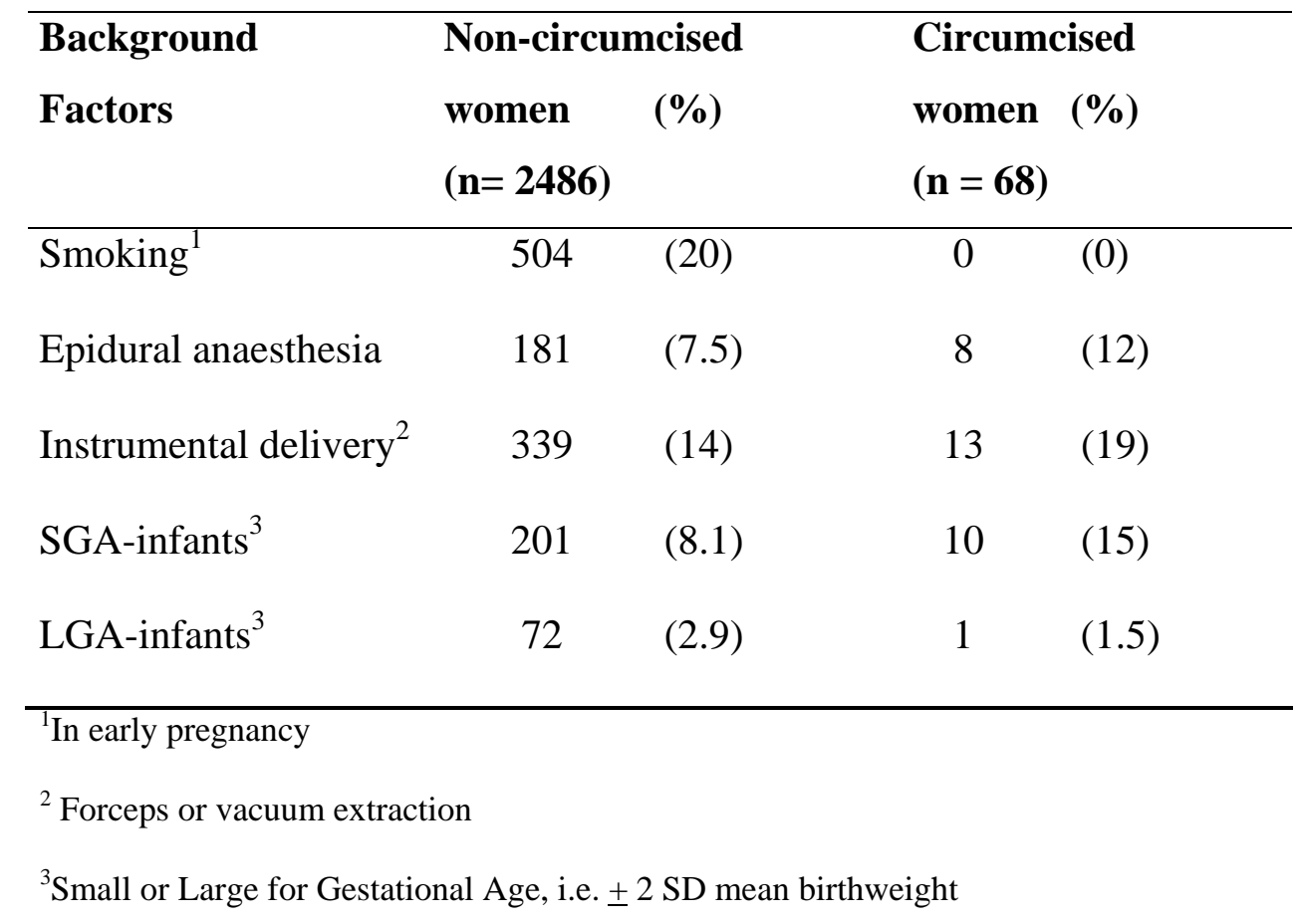


Table 2 Bivariate and adjusted relative risk regarding prolonged labour among circumcised $(n=68)$ and non-circumcised nulliparous women $(n=2486)$, giving birth in Sweden 1990-96

\section{Variables}

Bivariate OR (95\% CI) $\quad$ Adjusted $^{4}$ OR (95\% CI)

\section{Prolonged labour $^{1} \quad$ Prolonged labour $^{1}$}

Circumcised vs. non-circumcised $0.3 \quad(0.2-0.5)$

$0.2 \quad(0.2-0.5)$

Maternal age ${ }^{2}$

1.1

Birthweight deviation $^{3}$

Epidural anaesthesia

Augment with oxytocin

$3.3 \quad(2.8-4.0)$

\footnotetext{
${ }^{1}$ Second stage of labour $>60 \mathrm{~min}$.

${ }^{2}$ The OR is presented as risk for every additional 10 years period

${ }^{3}$ The OR is presented as risk for every $10 \%$ increase in birth-weight deviation

${ }^{4}$ Adjusted for age, birthweight deviation, epidural anaesthesia, and augment with oxytocin
} 


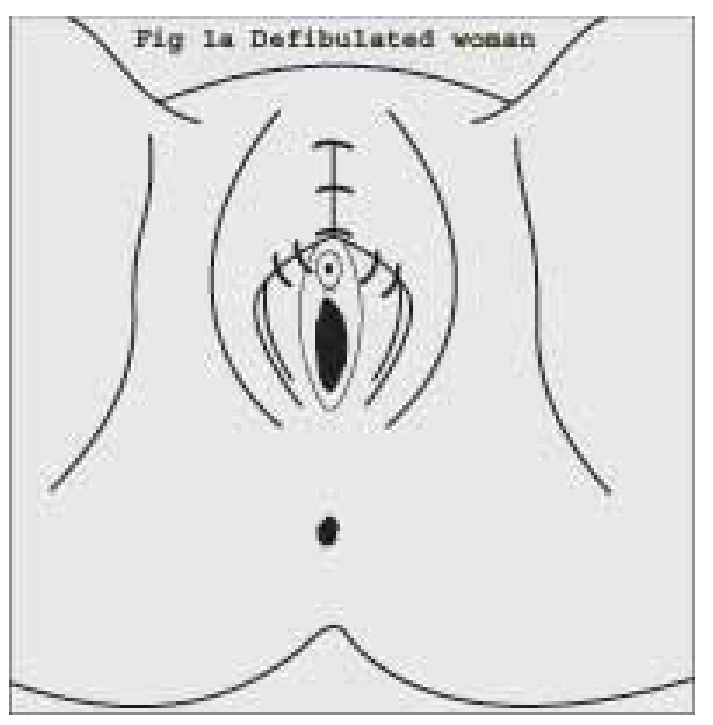




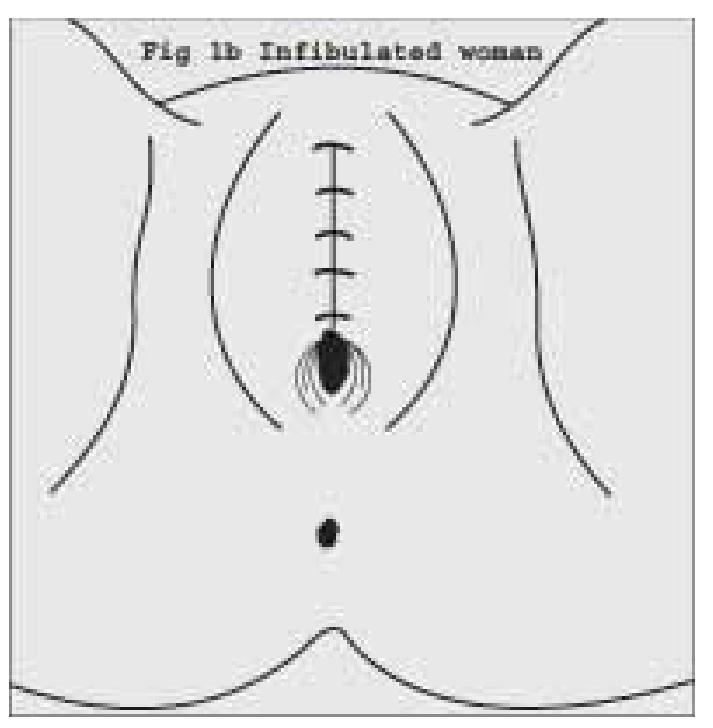

